\title{
Current status of rivaroxaban in elderly patients with pulmonary embolism (Review)
}

\author{
ZI-KAI SONG* , HONGYAN CAO*, HAIDI WU, QI WEI, MINGLONG TANG, \\ SHUO YANG, YANG LIU and LING QIN \\ Department of Cardiology, The First Hospital of Jilin University, Changchun, Jilin 130000, P.R. China
}

Received May 16, 2019; Accepted January 22, 2020

DOI: $10.3892 /$ etm.2020.8559

\begin{abstract}
Acute pulmonary embolism (PE) occurs with a high incidence rate in elderly patients, demonstrating complex clinical manifestations, as well as a difficult anticoagulant treatment strategy. Currently, there is limited understanding of the selection criteria for anticoagulant treatment in elderly patients with PE. In fact, the vitamin $\mathrm{K}$ antagonist warfarin, a commonly prescribed anticoagulant, has multiple disadvantages, including a narrow therapeutic range, unpredictable pharmacokinetics, multiple food and drug interactions and genetic polymorphisms resulting in poor response to this therapy; therefore, routine laboratory monitoring is required. Most elderly patients with PE fail to adhere to the treatment regimen or even discontinue it, and clinicians are equally hesitant to initiate oral anticoagulants in elderly patients with PE. This leads to a dilemma regarding the use of anticoagulation therapies and a worse prognosis for the patients. Rivaroxaban, a direct Xa factor inhibitor, has demonstrated considerable practical and clinical advantages, exhibits fast-start action pharmacokinetic and pharmacodynamic characteristics, and has an enhanced predictable anticoagulant effect with fewer drug-drug interactions. Based on randomized controlled trials and real-world clinical practice, rivaroxaban has also been recognized as a safe and effective anticoagulant, and these advantages have improved the therapeutic compliance of elderly patients with PE. Thus, this review focused on the current status of rivaroxaban treatment for elderly patients with PE, and described its significance in changing the current anticoagulation treatment regimens for patients. It is expected that rivaroxaban will become a good choice for the treatment of PE in elderly patients.
\end{abstract}

Correspondence to: Dr Ling Qin, Department of Cardiology, The First Hospital of Jilin University, 71 Xinmin Street, Changchun, Jilin 130000, P.R. China

E-mail: 15043022401@163.com

${ }^{*}$ Contributed equally

Key words: deep venous thrombosis, direct oral anticoagulants, elderly patients, pulmonary embolism, rivaroxaban, vitamin $\mathrm{K}$ antagonist

\section{Contents}

1. Introduction

2. Natural history of PE in elderly patients

3. Risk factors associated with PE in elderly patients

4. Pathogenesis and pathophysiology of PE in elderly patients

5. Clinical presentation of PE in elderly patients

6. Anticoagulation therapy in elderly patients with PE

7. Case study

8. Conclusion

\section{Introduction}

In recent years, the incidence of pulmonary embolism (PE) has been increasing in the elderly population; the incidence of venous thromboembolism (VTE), including PE and deep-vein thrombosis (DVT), is $<1 / 10,000$ people/year in non-elderly patients; however, it is $1 / 100$ people/year in elderly patients (1). In addition, the prevalence of PE in patients of $\geq 75$ years of age is 7-10 times higher compared with that in younger adults, demonstrating even higher levels in those of $\geq 85$ years of age $(2,3)$. The increased prevalence and incidence in populations of elderly patients result from multifactorial causes, including age-related hypercoagulation status and the coexistence of multiple diseases and conditions that result in endothelial injury, decreased blood flow and the activation of coagulation factors $(1,4,5)$.

In recent decades, the vitamin $\mathrm{K}$ antagonist warfarin has been used therapeutically for the treatment and prevention of PE (6-8); however, its use in elderly patients with PE is limited due to associated problems with the drug. Meanwhile, the non-vitamin $\mathrm{K}$ oral anticoagulant, rivaroxaban is observed to have improved efficacy as a pharmacological treatment in elderly patients with PE. Compared with warfarin, the advantages of rivaroxaban include a better efficacy-to-safety ratio, fewer food and drug interactions and a more rapid onset of action, with no requirements for routine coagulation monitoring $(9,10)$.

Nonetheless, the phase II clinical trials of the Einstein-DVT Dose-Ranging Study and the subsequent phase III EINSTEIN-DVT (11), EINSTEIN-PE (12) and EINSTEIN-extension (11) clinical trials reported that rivaroxaban is not inferior to vitamin $\mathrm{K}$ antagonists in its efficacy. 
However, these trials did observe that compared with the vitamin $\mathrm{K}$ antagonists, rivaroxaban demonstrated greater risk reductions for bleeding (especially major bleeding) in all participants with PE, including those who were elderly (12). Based on the results of the EINSTEIN-DVT and EINSTEIN-PE trials, the European Society of Cardiology issued guidelines on the diagnosis and management of acute PE in 2014 (13). Thus, due to the number of clinical studies on rivaroxaban use in elderly patients with PE increasing $(14,15)$, the current status of rivaroxaban use in elderly patients with PE should be reviewed.

This article reviewed relevant literature published before January 1, 2019 and 'Rivaroxaban and elderly and pulmonary embolism' was used as the PubMed (https://www.ncbi.nlm. nih.gov/pubmed) and Web of Science (www.isiknowledge. com) database search term. Based on the relevant primary research, review articles, guidelines and personal experience, this report summarized the current collective understanding of rivaroxaban use in elderly patients with PE with an aim to help professionals to make well-informed clinical decisions in daily practice.

\section{Natural history of PE in elderly patients}

The epidemiology of PE in elderly populations is difficult to determine, as PE is present in $\sim 1 / 3$ of elderly patients with VTE and, compared with DVT, the mortality rate from PE is much greater in this population $(12,13,16)$. Each year, PE occurs in $\sim 1$ in 10,000 people aged $20-30$ years old and $\sim 8$ in 1,000 people aged 85 years or above (17). Thus, it is more frequently diagnosed in patients aged $80-84$ years (18), with its incidence rate increasing to $\sim 8$ in 1,000 people/year in those aged 85 or older, which is $\sim 100$ times higher compared with people aged 45 years or younger $(1,19)$. In addition, the risk of VTE recurrence (15-20\% per decade) increases with age; $60 \%$ of thrombolytic events occur in patients of $>70$ years $(2,3)$.

As the world's population ages, the incidence of PE in elderly patients has increased significantly $(2,3)$. In the elderly population, the risk of $\mathrm{PE}$ is increased is $>90 \%$, which indicates that $90 \%$ of the total incidence of thrombosis in the population can be attributed to aging. Upon comparing PE incidence values among younger and elderly populations, it has been revealed that aging is one of the strongest and most common risk factors for venous thrombotic disease and the subsequent high incidence of VTE in the elderly population $(3,19)$. In addition, due to elderly patients being more likely to exhibit comorbidities that are also risk factors for PE (discussed further in the next section), they demonstrate higher mortality rates compared with non-elderly patients $(17,20,21)$. In fact, a longitudinal population-based study observed that VTE is predominantly a disease associated with older age, and that during the 25-year study period, only four events of VTE in patients of $<15$ years of age were recorded (22).

\section{Risk factors associated with PE in elderly patients}

The first studies on the natural history of VTE were performed inorthopedic surgery settings in the 1960s (23). PE results from interactions between patient-related (usually permanent) and environment-related (usually temporary or reversible) risk factors (13). The temporary or reversible risk factors for PE in all populations include: Major trauma, immobilization, lower limb fracture, joint replacement, surgery, spinal cord injury, cancer, a central venous line, infection, blood transfusion, serious chronic medical conditions, myocardial infarction, heart failure, cigarette smoking, obesity, hypercholesterolemia, atherosclerosis, hypertension, diabetes mellitus and oral contraception or pregnancy $(12,13)$. Of these risk factors, the most common in elderly patients are recent immobility, infection, surgery, cancer, chronic cardiopulmonary and renal dysfunction, hypercholesterolemia, atherosclerosis, hypertension, diabetes mellitus and venous insufficiency (Table I) (24-28), with multiple risk factors usually identified during the diagnostic evaluation of VTE in elderly patients.

Medicine is gradually adapting to the challenges presented by a rapidly aging society. Although 'aging' itself is not a disease, elderly people are more likely to have illnesses associated with conventional risk factors, and risk factors may develop, worsen and accumulate over a lifetime. The factors that affect PE risk are not entirely understood in the elderly population, but they likely originate from multiple etiologies derived from the physiological characteristics inherent to this population (Table I). For example, age-related thrombosis and hemostatic changes may increase the risk of PE in elderly patients (21); levels of the coagulation factors V, VII, VIII, von Willebrand factor and blood plasma fibrinogen increase with aging (29); changes in levels of fibrinolytic proteins and components of the fibrinolytic pathway, such as plasminogen activator inhibitor-1, are also associated with aging $(30,31)$; and hyperhomocysteinemia and myeloproliferative disorders that lead to vascular endothelial injury commonly occur in elderly patients (29). As a result, tissue factors and collagen are exposed, which contribute to the development of a hypercoagulable state and thrombosis (29). These aging-related changes result in the activation and accumulation of platelets, red blood cells and other cellular components that activate the coagulation cascade (21,30-34).

\section{Pathogenesis and pathophysiology of PE in elderly patients}

PE involves both the circulatory and respiratory systems; it first develops in the right ventricle (RV), resulting in $\mathrm{RV}$ dilation and failure due to an increased pressure overload. Concurrently, due to RV dysfunction and the exacerbated ventricular desynchronization, the left ventricular blood volume and ejection fraction are also reduced. These changes result in systemic hypotension, hemodynamic instability and even death (35).

Advanced age is often associated with an increased risk of coronary heart disease (36). Pulmonary artery pressure increases when at least $30-50 \%$ of the total cross-sectional area of the pulmonary artery bed is blocked by thrombi, and the secondary angina and cardiogenic shock that can develop due to decreased left ventricular filling and ejection fraction can culminate in an increased mortality risk $(35,37)$. PE also causes vasoconstriction and the subsequent release of inflammatory cytokines and epinephrine (34). These changes further contribute to the increased pressure in the pulmonary artery and lead to increases in wall tension, myocyte stretch, elevated 


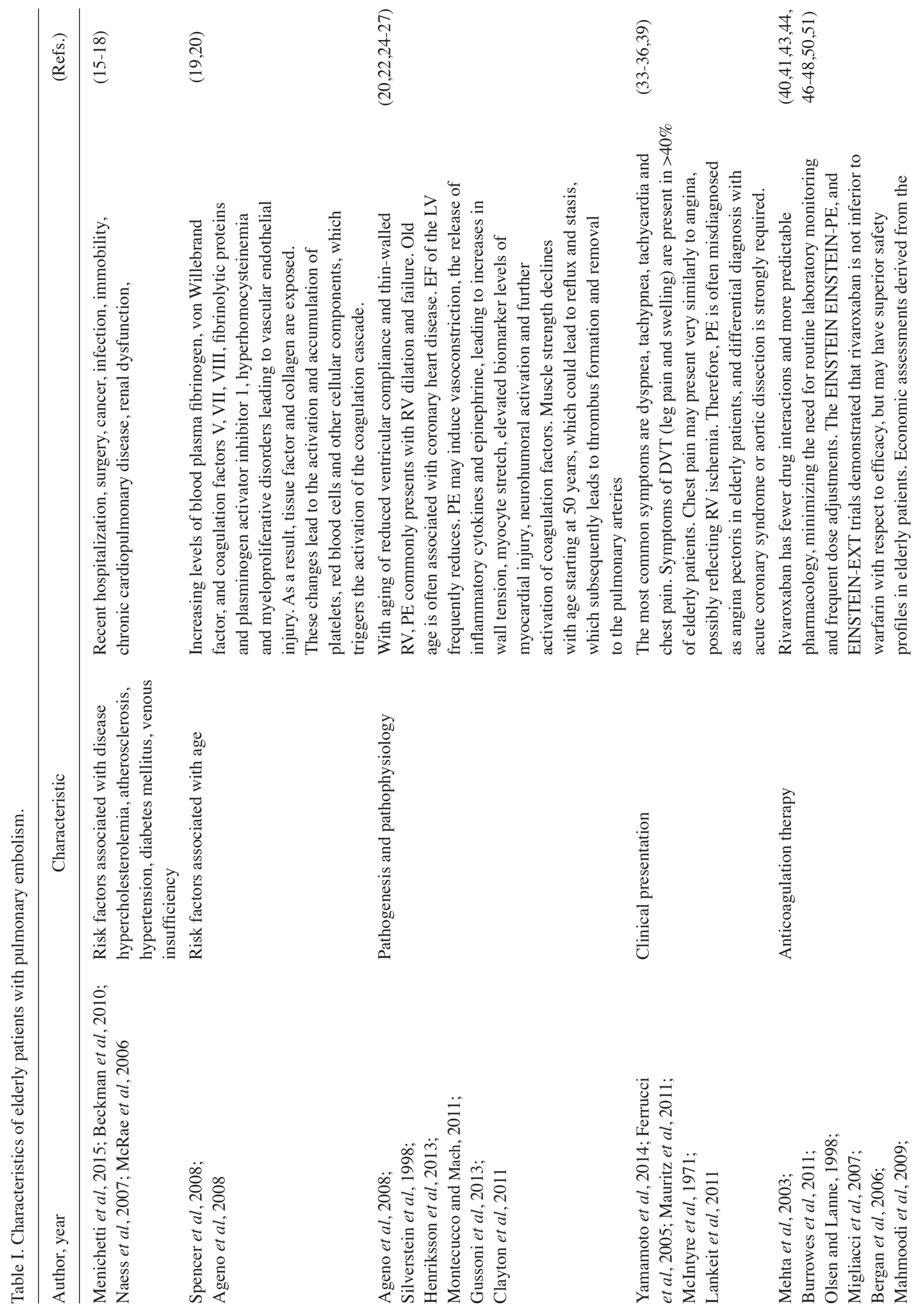


biomarker levels of myocardial injury, neurohumoral activation and further activation of coagulation factors (38-40). Although compensatory RV dilation may occur, the extent of immediate adaptation is limited, especially in elderly patients whose reduced ventricular compliance and thin-walled RV cannot tolerate an average pulmonary artery pressure of $>40 \mathrm{mmHg}$ (35). In addition, despite the most direct effects of $\mathrm{PE}$ involving the circulatory system, respiratory failure is often the consequence of hemodynamic disturbances that occur during PE $(35,41)$; a low cardiac output leads to the desaturation of the mixed venous blood and a mismatch between ventilation-perfusion, conditions that contribute to hypoxemia. Nevertheless, small distal emboli do not affect hemodynamics, but they can create areas of alveolar hemorrhage and subsequent hemoptysis, pleuritis and pleural effusion (14).

Muscle strength, which also affects the calf muscle pump, declines with age, starting at 50 years (42). Over time, decreased calf muscle compliance and capacitance response are indicators for the redistribution of peripheral venous blood to the central circulation (43). The roles of lower extremity muscle strength and the accompanying deterioration in venous hemodynamics have yet to be clarified; however, reduced calf muscle pump function may contribute to reflux, stasis and thrombus formation, and removal to the pulmonary arteries.

Endothelial dysfunction results in changes to the mechanisms that reduce vasodilation and promote prothrombic characteristics, and it is an important age-related cardiovascular phenomenon (44). With aging, modifications that occur in the arterial and venous vessel walls include atrophy of muscle fibers and valve thickening due to increases in collagen fiber numbers $(42,45)$. Aging is also associated with reduced anticoagulant properties of the endothelium and reduced endothelial thromboresistance (29). Varicose veins can also reduce the release of anti-inflammatory and anticoagulant agents (46). Therefore, the remodeling of the venous vessel wall with aging may increase the risk of thrombosis in elderly patients. Furthermore, the increased risk of VTE is associated with microalbuminuria, which may result from endothelial dysfunction (47). Chronic venous insufficiency occurs when valves in the leg veins fail through the remodeling of the valve leaflets or dilation of the venous wall. These changes subsequently contribute to stasis and the elevation of distal venous blood pressure $(42,45)$. The prevalence of this functional disorder is greater in older populations (48).

\section{Clinical presentation of PE in elderly patients}

The clinical presentation of PE can range from being asymptomatic, to mild chest discomfort, to severe chest pain and shortness of breath, to sudden death caused by a large PE (13). In most patients, $\mathrm{PE}$ is diagnosed based on the shortness of breath, chest pain, hemoptysis, pre-syncope or syncope, or a combination of these symptoms and clinical signs $(49,50)$. However, in some instances, PE may be completely asymptomatic and can be found incidentally during diagnostic examinations for other disorders or at autopsy. For example, in elderly patients, the presenting symptoms and signs of PE often lack specificity, which makes diagnosis difficult (51); most commonly, these include shortness of breath, chest pain, tachypnea, and tachycardia, alongside less common symptoms 
such as syncope, hemoptysis, cough, hypoxemia and fatigue. DVT symptoms, such as leg pain and swelling are also present in $>40 \%$ of elderly patients with PE (29). Chest discomfort or pain is another common symptom of PE that is usually caused by pleural irritation associated with the presence of distal emboli, the resulting pulmonary infarction, or both $(11,12,52)$. In central PE, the chest pain may also exhibit typical angina features that reflect RV ischemia, which must be differentiated from acute coronary syndrome or aortic dissection during diagnosis; however, due to chest pain experienced by patients with angina pectoris or PE presenting very similarly, PE is often misdiagnosed as angina pectoris in elderly patients (13). Also, regardless of the presence of hemodynamic instability, syncope is not uncommon and is often the first sign of PE at any age $(51,53)$, but especially amongst older adults. In fact, one study identified PE in nearly one of every six patients hospitalized for a first episode of syncope (54). Of the patients whose first PE-associated hospital admission was due to syncope, $80.4 \%$ were $>70$ years of age, and $46.4 \%$ were $>80$ years of age.

However, to the best of our knowledge to date, no single symptom or sign can be used to accurately diagnose or rule out PE in elderly patients, and few studies have comprehensively and prospectively compared the manifestations of VTE in elderly and younger adults. Thus, clinicians must use more precise clinical tools and maintain a high level of incertitude when considering VTE as a diagnosis in elderly patients $(2,29,55)$.

\section{Anticoagulation therapy in elderly patients with PE}

Currently, standard PE therapeutic regimens include the initial treatment with heparin, followed by warfarin (56-58). As an anticoagulant, heparin increases the activity of antithrombin, which inhibits coagulation factors; therefore, the lack of antithrombin often affects the efficacy of anticoagulant therapies (57). Although low molecular weight heparin does not require routine coagulation monitoring, heparin has limited use in some patients with heparin-induced thrombocytopenia (59). In addition, since, heparin is a parenteral anticoagulant, its administration can be challenging for patients, as it must be injected subcutaneously, making it inconvenient and difficult to use at home.

Warfarin, a vitamin $\mathrm{K}$ antagonist, exerts anticoagulant effects by inhibiting vitamin $\mathrm{K}$, thereby subsequently activates clotting factors produced by the liver; however, as warfarin is primarily metabolized in the liver through the cytochrome P450 (CYP450) enzymes, the combination of warfarin and other drugs metabolized by the CYP450 pathways will affect the metabolism of warfarin (60). For example, certain cardiovascular drugs, such as amiodarone, digoxin and propranolol; antibiotics, such as rifampin, erythromycin, clarithromycin and metronidazole; antifungal drugs, such as fluconazole; and sedative drugs, such as barbiturates, have been demonstrated to increase or decrease the blood concentration of warfarin, which further affects its therapeutic effect (13). Thus, it is difficult to maintain a continuous, stable anticoagulant effect with warfarin (58). In addition, frequent laboratory monitoring and dosage changes, arrow therapeutic range, unpredictable pharmacokinetics, multiple food and drug interactions, and certain population of patients presenting with genetic polymorphisms which cannot respond to warfarin $(57,58,61)$, make it more difficult to maintain stable anticoagulation with warfarin, especially in the elderly population. For example, a previous study reported that $>70 \%$ of patients with a high risk of VTE recurrence did not receive warfarin therapy and that $>50 \%$ of patients stop warfarin treatment within 1 year (62), whilst another study found that more than one-half of patients switch to rivaroxaban after receiving warfarin (56). The primary reasons for this change in treatment included patient choice and difficulties in managing international normalized ratio (INR) instability; the EINSTEIN-DVT and EINSTEIN-PE trials demonstrated that the INR of patients receiving warfarin was within the therapeutic range of 62.7 and $57.7 \%(11,12)$. Thus, these studies suggested that there are numerous difficulties associated with warfarin management. Furthermore, due to unstable vitamin $\mathrm{K}$ absorption and metabolism, elderly patients are required to visit the hospital frequently for routine coagulation monitoring whilst using warfarin (63-65). Due to these required visits being unsustainable for most elderly patients, the duration of anticoagulation is negatively affected in these patients with PE, which further leads to a poor prognosis.

Age-related changes in body composition, such as relative increases in body fat due to decreased lean body mass and total body water, may also alter the pharmacodynamics of drugs (66). Decreased serum albumin concentrations may reduce the volume of anticoagulants distributed throughout the body, which results in an increased sensitivity to the standard dosage. In addition, due to a limited dietary intake or reduced vitamin $\mathrm{K}$ absorption, elderly patients have a reduced ability to adjust the levels of coagulation factors, which may also have a direct effect on an anticoagulation therapeutic regimen $(67,68)$.

As elderly patients often present with comorbidities and require multiple medications, this population requires a $\mathrm{PE}$ therapy regimen with fewer drug and food interactions. In fact, it is well known that warfarin management is frequently complicated by dietary and medication interactions, which are more prevalent in elderly patients (65). Upon administration of warfarin, these interactions lead to INR instability and may explain the positive results obtained in elderly patients using rivaroxaban $(1,69,70)$, a novel oral anticoagulant which belongs to a group of anticoagulants that targets specific sites in the coagulation cascade (10). Rivaroxaban directly inhibits Xa factor activation, and owing to its predictable bioavailability and pharmacokinetics, the additional benefit of rivaroxaban compared with warfarin is that when prescribed at fixed doses concomitantly with other drugs, fewer drug interactions occur (9). These characteristics minimize the need for routine coagulation monitoring and frequent dosage adjustments (71). To date, rivaroxaban has been approved in numerous countries for the treatment and prevention of recurrent VTE; the drug demonstrates the same efficacy as warfarin, but poses a lower risk of bleeding, and is approved for the prevention of stroke in patients with nonvalvular atrial fibrillation (72), and for the prevention and treatment of DVT and PE $(11,12)$, especially following knee and hip replacements (73). One study found that compared with warfarin, the treatment of stable atherosclerotic vascular disease using 

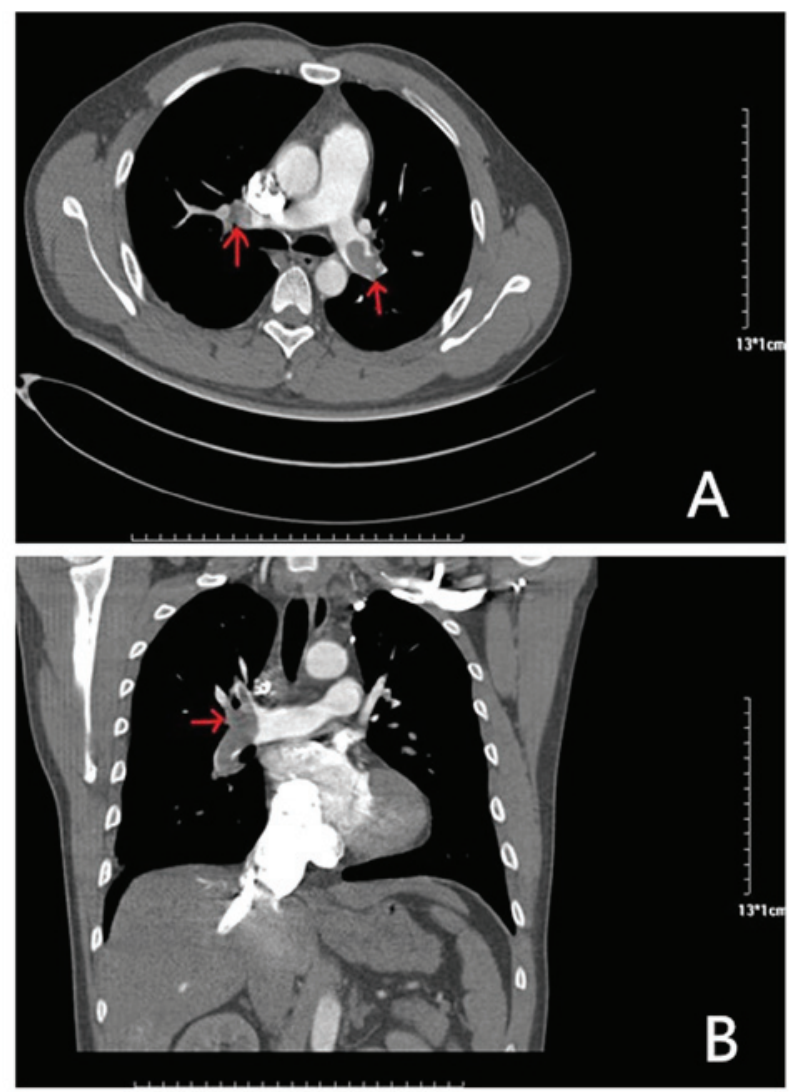

Figure 1. Results of computed tomography pulmonary angiography before rivaroxaban treatment. (A) Axial CT enhancement showed that filling defects in both pulmonary arteries (indicated by the red arrow) are thrombi. (B) CT-enhanced coronary reconstruction showing a thrombus in the filling defect of the right pulmonary artery (indicated by the red arrow).

rivaroxaban with aspirin resulted in enhanced cardiovascular outcomes (74).

The EINSTEIN $(34.5 \%$ of participants were $>65$ years), EINSTEIN-PE (39.1\% of participants were $\geq 65$ years) and EINSTEIN-extension trials $(38.6 \%$ of participants were $\geq 65$ years) reported that in elderly patients, rivaroxaban was not inferior to warfarin in its efficacy, but may exhibit improved safety features $(11,12)$. A systematic review and meta-analysis on the efficacy and harms of the use of direct oral anticoagulants for stroke prevention in atrial fibrillation and secondary prevention of VTE in elderly participants (aged $\geq 75$ years) found that the efficacy of rivaroxaban for managing thrombotic risks was superior compared with that of warfarin. Compared with warfarin, rivaroxaban also demonstrated a significantly lower risk for major bleeding (5).

Rivaroxaban also has considerable advantages when used for patients with poor INR control or who are warfarin intolerant. Patients with mild (creatinine clearance, $50-80 \mathrm{ml} / \mathrm{min}$ ) or moderate (creatinine clearance, $30-49 \mathrm{ml} / \mathrm{min}$ ) renal injury could be treated with rivaroxaban without a dose reduction (12). Notably, a previous study on a large nationwide cohort of Danish patients (mean age, 62.6 years) with incident unprovoked VTE also observed that rivaroxaban treatment was associated with lower risks of recurrent DVT and PE compared with the standard treatment (75).
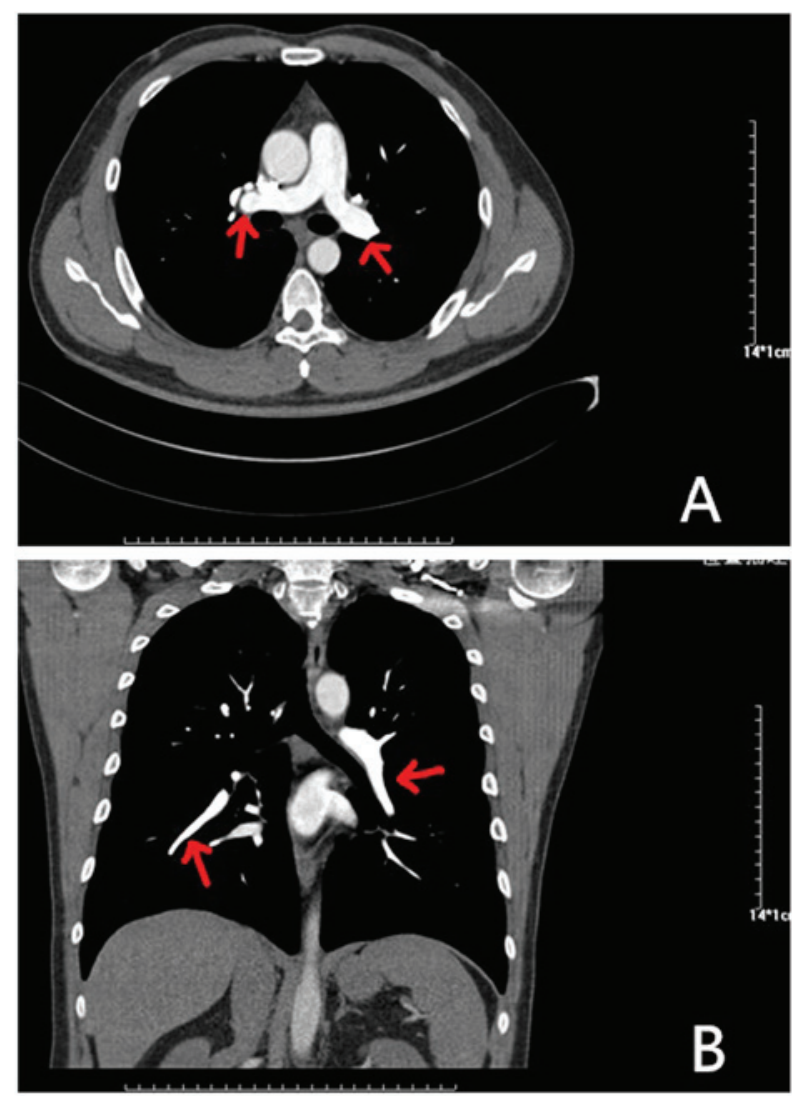

Figure 2. Results of computed tomography pulmonary angiography after 90 days of rivaroxaban treatment. (A) Axial CT enhancement revealed the disappearance of bilateral pulmonary filling defects (indicated by the red arrow). (B) CT-enhanced coronary reconstruction shows that the filling defect of the right pulmonary artery (indicated by the red arrow) has disappeared.

Because most of these clinical trials included large proportions of participants of $\geq 75$ years of age, relatively reliable subgroup comparisons could be performed. Compared with warfarin, rivaroxaban may provide some safety and efficacy advantages when used to treat elderly patients $(75,76)$. In addition, a retrospective observational study comparing the hospital length of stay (LOS) and hospital costs for patients with VTE treated with rivaroxaban versus those treated with warfarin found that patients in hospital for VTE treatment (22.9\% were $>65-70$ years of age; $32.3 \%$ were $>75$ years of age) who were treated with rivaroxaban demonstrated a significantly shorter mean LOS (1.57 days shorter). Due to there being fewer days from the first treatment dose to discharge, the hospitalization costs were also significantly lower $(77,78)$. In addition, the EINSTEIN trials found that shorter rivaroxaban-associated LOSs occurred at all included hospitals in all countries, because the patients did not need to be hospitalized before the transition from heparin and warfarin to warfarin only (11). Similarly, the subsequent economic assessments of EINSTEIN trial data revealed that rivaroxaban use was associated with cost savings and longer quality-adjusted years of life (79).

For most patients, a baseline assessment of bleeding risk, measurements of kidney and liver function, platelet counts, baseline coagulation assays and a thorough medication review are necessary before anticoagulant therapy is initiated (80). However, the unique aspects of anticoagulation therapy 
strategies in elderly patients warrant careful attention to initial drug and dosage determinations and subsequent monitoring, with physicians often delaying or declining the prescription of an anticoagulant in elderly patients to avoid the increased risk of adverse events. Specific reversal agents for factor Xa inhibitors are in late-stage development (81).

\section{Case study}

An 81-year-old female presented at the hospital with dyspnea, which became increasingly worse over 1 month; the patient had no previous medical history and was not receiving any medication. Her symptoms were worse following mild activity and were relieved after stopping activity without medication. On admission, the patient was fully conscious, with a blood pressure of 140/64 $\mathrm{mmHg}$, a regular heart rate of $100 \mathrm{bpm}$ on auscultation and an oxygen saturation of $92 \%$. She presented with mild edema in her left lower limbs, but the remainder of her physical examination was normal. Results of platelets, hemoglobin and cardiac troponin-T levels, in addition to liver function, kidney function and electrolytes, were all normal. Routine coagulation assays, such as activated partial thromboplastin time, prothrombin time and INR were also normal. However, the D-dimer and N-terminal pro-brain natriuretic peptide concentrations were high, and arterial blood gas levels were reduced compared with normal levels. The results of the electrocardiogram and transthoracic echocardiogram were also normal, but lower limb venous compression ultrasonography revealed a left intermuscular vein thrombus. In addition, computed tomography pulmonary angiography found the presence of an embolus in the main left and right pulmonary artery (Fig. 1). Thus, $15 \mathrm{mg}$ rivaroxaban was prescribed twice daily. Following 7 days of oral rivaroxaban, the dyspnea improved, arterial blood gases increased and D-dimer levels decreased. After 3 weeks, rivaroxaban was adjusted to $20 \mathrm{mg}$ once daily and at the 90-day follow-up, the patient had no complaints of discomfort, and venous compression ultrasonography and computed tomography pulmonary angiography results had returned to normal (Fig. 2). Thus, treatment was terminated.

\section{Conclusion}

Anticoagulation treatment strategies in elderly patients with $\mathrm{PE}$ are changing. Based on the results of randomized controlled trials and real-world clinical practice, rivaroxaban has been recognized as a safe and effective anticoagulant and it has demonstrated significant promise as an anticoagulation treatment for patients with PE. Of note, the pharmacokinetic and pharmacodynamic characteristics of rivaroxaban have markedly improved the therapeutic compliance of elderly patients with PE. Thus, rivaroxaban is expected to become a favorable choice for the treatment of PE in elderly patients.

\section{Acknowledgements}

Not applicable.

\section{Funding}

No funding was received.

\section{Availability of data and materials}

All data generated or analyzed during the current study are included in this published article.

\section{Authors' contributions}

QW was responsible for the data curation; SY, MT and YL collected the resources for the study and presented the case study; ZKS wrote the original draft of the manuscript; and LQ, HC, HW and QW all reviewed and edited the final draft of the manuscript. All authors read and approved the final manuscript.

\section{Ethics approval and consent to participate}

Approval for the case report was waived by the First Hospital of Jilin University Ethical Board, based upon their policy of reviewing all intervention and observational studies except for case reports.

\section{Patient consent for publication}

The patient provided informed consent for the publication of their clinical data. The presented data are anonymized and risk of identification is minimal.

\section{Competing interests}

The authors declare that they have no competing interests.

\section{References}

1. Engbers MJ, van Hylckama Vlieg A and Rosendaal FR: Venous thrombosis in the elderly: Incidence, risk factors and risk groups. J Thromb Haemost 8: 2105-2112, 2010.

2. Spencer FA, Gurwitz JH, Schulman S, Linkins LA, Crowther MA, Ginsberg JS, Lee AY, Saczynski JS, Anand S, Lessard D, et al: Venous thromboembolism in older adults: A community-based study. Am J Med 127: 530-537.e3, 2014.

3. Stein PD, Hull RD, Kayali F, Ghali WA, Alshab AK and Olson RE: Venous thromboembolism according to age: The impact of an aging population. Arch Intern Med 164: 2260-2265, 2004.

4. Karamichalakis N, Georgopoulos S, Vlachos K, Liatakis I, Efremidis M, Sideris A and Letsas KP: Efficacy and safety of novel anticoagulants in the elderly. J Geriatr Cardiol 13: 718-723, 2016.

5. Sharma M, Cornelius VR, Patel JP, Davies JG and Molokhia M: Efficacy and harms of direct oral anticoagulants in the elderly for stroke prevention in atrial fibrillation and secondary prevention of venous thromboembolism: Systematic review and meta-analysis. Circulation 132: 194-204, 2015.

6. Gallus A, Jackaman J, Tillett J, Mills W and Wycherley A: Safety and efficacy of warfarin started early after submassive venous thrombosis or pulmonary embolism. Lancet 2: 1293-1296, 1986.

7. Hirsh J: Low-molecular-weight heparin vs. Warfarin for prophylaxis against deep-vein thrombosis. N Engl J Med 330: 863, 1994.

8. Monreal M, Foz M and Audi L: Warfarin to prevent thromboembolism in chronic atrial fibrillation. Lancet 1: 720-721, 1989.

9. Buller HR, Lensing AW, Prins MH, Agnelli G, Cohen A, Gallus AS, Misselwitz F, Raskob G, Schellong S and Segers A; Einstein-DVT Dose-Ranging Study investigators: A dose-ranging study evaluating once-daily oral administration of the factor $\mathrm{Xa}$ inhibitor rivaroxaban in the treatment of patients with acute symptomatic deep vein thrombosis: The Einstein-DVT Dose-Ranging Study. Blood 112: 2242-2247, 2008. 
10. Scaglione F: New oral anticoagulants: Comparative pharmacology with vitamin K antagonists. Clin Pharmacokinet 52: 69-82, 2013.

11. EINSTEIN Investigators, Bauersachs R, Berkowitz SD, Brenner B, Buller HR, Decousus H, Gallus AS, Lensing AW, Misselwitz F, Prins MH, et al: Oral rivaroxaban for symptomatic venous thromboembolism. N Engl J Med 363: 2499-2510, 2010.

12. EINSTEIN-PE Investigators, Büiller HR, Prins MH, Lensin AW, Decousus H, Jacobson BF, Minar E, Chlumsky J, Verhamme P, Wells $\mathrm{P}$, et al: Oral rivaroxaban for the treatment of symptomatic pulmonary embolism. N Engl J Med 366: 1287-1297, 2012.

13. Konstantinides SV, Torbicki A, Agnelli G, Danchin N, Fitzmaurice D, Galiè N, Gibbs JS, Huisman MV, Humbert M, Kucher N, et al: 2014 ESC guidelines on the diagnosis and management of acute pulmonary embolism. Eur Heart J 35: 3033-3069, 2014.

14. Mayr A, Klug G, Greulich S, Metzler B and Feuchtner G: Serpentine-like right atrial mass and fulminant bilateral pulmonary embolism during treatment with rivaroxaban. Int $\mathrm{J}$ Cardiovasc Imaging 32: 1001-1002, 2016.

15. Menichetti M, Rosso S, Menegatti E and Pazzaglia M: Use of rivaroxaban in an elderly patient with intermediate-low early mortality risk due to pulmonary embolism: A case report. J Med Case Rep 9: 274, 2015.

16. Beckman MG, Hooper WC, Critchley SE and Ortel TL: Venous thromboembolism: A public health concern. Am J Prev Med 38 (Suppl 4): S495-S501, 2010.

17. Naess IA, Christiansen SC, Romundstad P, Cannegieter SC, Rosendaal FR and Hammerstrom J: Incidence and mortality of venous thrombosis: A population-based study. J Thromb Haemost 5: 692-699, 2007.

18. McRae S, Tran H, Schulman S, Ginsberg J and Kearon C: Effect of patient's sex on risk of recurrent venous thromboembolism: A meta-analysis. Lancet 368: 371-378, 2006.

19. Spencer FA, Gore JM, Lessard D, Emery C, Pacifico L, Reed G, Gurwitz JH and Goldberg RJ: Venous thromboembolism in the elderly. A community-based perspective. Thromb Haemost 100: 780-788, 2008

20. Ageno W, Agnelli G, Imberti D, Moia M, Palareti G, Pistelli R, Rossi R and Verso M; MASTER Investigators: Risk factors for venous thromboembolism in the elderly: Results of the master registry. Blood Coagul Fibrinolysis 19: 663-667, 2008.

21. Andreotti F, Rocca B, Husted S, Ajjan RA, ten Berg J, Cattaneo M, Collet JP, De Caterina R, Fox KA, Halvorsen S, et al: Antithrombotic therapy in the elderly: Expert position paper of the european society of cardiology working group on thrombosis. Eur Heart J 36: 3238-3249, 2015.

22. Silverstein MD, Heit JA, Mohr DN, Petterson TM, O'Fallon WM and Melton LJ III: Trends in the incidence of deep vein thrombosis and pulmonary embolism: A 25-year population-based study. Arch Intern Med 158: 585-593, 1998.

23. Kakkar VV, Howe CT, Flanc C and Clarke MB: Natural history of postoperative deep-vein thrombosis. Lancet 2: 230-232, 1969.

24. Henriksson P, Westerlund E, Wallen H, Brandt L, Hovatta O and Ekbom A: Incidence of pulmonary and venous thromboembolism in pregnancies after in vitro fertilisation: Cross sectional study. BMJ 346: e8632, 2013

25. Montecucco F and Mach F: Should we focus on 'venous vulnerability' instead of 'plaque vulnerability' in symptomatic atherosclerotic patients? Thromb Haemost 106: 995-996, 2011.

26. Gussoni G, Frasson S, La Regina M, Di Micco P and Monreal M; RIETE Investigators: Three-month mortality rate and clinical predictors in patients with venous thromboembolism and cancer. Findings from the RIETE registry. Thromb Res 131: 24-30, 2013.

27. Clayton TC, Gaskin M and Meade TW: Recent respiratory infection and risk of venous thromboembolism: Case-control study through a general practice database. Int J Epidemiol 40: 819-827, 2011.

28. Sweetland S, Beral V, Balkwill A, Liu B, Benson VS, Canonico M, Green J and Reeves GK; Million Women Study Collaborators: Venous thromboembolism risk in relation to use of different types of postmenopausal hormone therapy in a large prospective study. J Thromb Haemost 10: 2277-2286, 2012.

29. Johnson SA, Eleazer GP and Rondina MT: Pathogenesis, diagnosis, and treatment of venous thromboembolism in older adults. J Am Geriatr Soc 64: 1869-1878, 2016.

30. Mohebali D, Kaplan D, Carlisle M, Supiano MA and Rondina MT: Alterations in platelet function during aging: Clinical correlations with thromboinflammatory disease in older adults. J Am Geriatr Soc 62: 529-535, 2014.
31. van Hylckama Vlieg A and Rosendaal FR: High levels of fibrinogen are associated with the risk of deep venous thrombosis mainly in the elderly. J Thromb Haemost 1: 2677-2678, 2003.

32. Oger E, Lacut K, Van Dreden P, Bressollette L, Abgrall JF, Blouch MT, Scarabin PY and Mottier D: High plasma concentration of factor VIII coagulant is also a risk factor for venous thromboembolism in the elderly. Haematologica 88: 465-469, 2003.

33. Yamamoto K, Takeshita $\mathrm{K}$ and Saito $\mathrm{H}$ : Plasminogen activator inhibitor-1 in aging. Semin Thromb Hemost 40: 652-659, 2014.

34. Ferrucci L, Corsi A, Lauretani F, Bandinelli S, Bartali B, Taub DD, Guralnik JM and Longo DL: The origins of age-related proinflammatory state. Blood 105: 2294-2299, 2005.

35. Mauritz GJ, Marcus JT, Westerhof N, Postmus PE and Vonk-Noordegraaf A: Prolonged right ventricular post-systolic isovolumic period in pulmonary arterial hypertension is not a reflection of diastolic dysfunction. Heart 97: 473-478, 2011.

36. McIntyre KM and Sasaha, a AA: The hemodynamic response to pulmonary embolism in patients without prior cardiopulmonary disease. Am J Cardiol 28: 288-294, 1971.

37. Madhavan MV, Gersh BJ, Alexander KP, Granger CB and Stone GW: Coronary Artery Disease in Patients $\geq 80$ Years of Age. J Am Coll Cardiol 71: 2015-2040, 2018.

38. Lankhaar JW, Westerhof N, Faes TJ, Marques KM, Marcus JT, Postmus PE and Vonk-Noordegraaf A: Quantification of right ventricular afterload in patients with and without pulmonary hypertension. Am J Physiol Heart Circ Physiol 291: H1731-H1737, 2006.

39. Lankeit M, Jimenez D, Kostrubiec M, Dellas C, Hasenfuss G, Pruszczyk P and Konstantinides S: Predictive value of the high-sensitivity troponin $\mathrm{T}$ assay and the simplified Pulmonary Embolism Severity Index in hemodynamically stable patients with acute pulmonary embolism: A prospective validation study. Circulation 124: 2716-2724, 2011.

40. Mehta NJ, Jani K and Khan IA: Clinical usefulness and prognostic value of elevated cardiac troponin I levels in acute pulmonary embolism. Am Heart J 145: 821-825, 2003.

41. Burrowes KS, Clark AR and Tawhai MH: Blood flow redistribution and ventilation-perfusion mismatch during embolic pulmonary arterial occlusion. Pulm Circ 1: 365-376, 2011.

42. Larsson L, Grimby G and Karlsson J: Muscle strength and speed of movement in relation to age and muscle morphology. J Appl Physiol Respir Environ Exerc Physiol 46: 451-456, 1979.

43. Olsen $\mathrm{H}$ and Lanne T: Reduced venous compliance in lower limbs of aging humans and its importance for capacitance function. Am J Physiol 275: H878-H886, 1998.

44. Migliacci R, Becattini C, Pesavento R, Davi G, Vedovati MC, Guglielmini G, Falcinelli E, Ciabattoni G, Dalla Valle F, Prandoni $\mathrm{P}$, et al: Endothelial dysfunction in patients with spontaneous venous thromboembolism. Haematologica 92: 812-818, 2007.

45. Chopard RP, Miranda Neto MH, Biazotto W and Molinari SL: Age-related changes in the human renal veins and their valves. Ital J Anat Embryol 99: 91-101, 1994.

46. Bergan JJ, Schmid-Schonbein GW, Smith PD, Nicolaides AN, Boisseau MR and Eklof B: Chronic venous disease. N Engl J Med 355: 488-498, 2006.

47. Mahmoodi BK, Gansevoort RT, Veeger NJ, Matthews AG, Navis G, Hillege HL and van der Meer J; Prevention of Renal and Vascular End-stage Disease (PREVEND) Study Group: Microalbuminuria and risk of venous thromboembolism. JAMA 301: 1790-1797, 2009.

48. Carpentier P and Priollet P: Epidemiology of chronic venous insufficiency. Presse Med 23: 197-201, 1994 (In French).

49. Miniati M, Prediletto R, Formichi B, Marini C, Di Ricco G, Tonelli L, Allescia G and Pistolesi M: Accuracy of clinical assessment in the diagnosis of pulmonary embolism. Am J Respir Crit Care Med 159: 864-871, 1999.

50. Pollack CV, Schreiber D, Goldhaber SZ, Slattery D, Fanikos J, O'Neil BJ, Thompson JR, Hiestand B, Briese BA, Pendleton RC, et al: Clinical characteristics, management, and outcomes of patients diagnosed with acute pulmonary embolism in the emergency department: initial report of EMPEROR (Multicenter Emergency Medicine Pulmonary Embolism in the Real World Registry). J Am Coll Cardiol 57: 700-706, 2011.

51. Robert-Ebadi H and Righini M: Diagnosis and management of pulmonary embolism in the elderly. Eur J Intern Med 25: 343-349, 2014.

52. Stein PD and Henry JW: Clinical characteristics of patients with acute pulmonary embolism stratified according to their presenting syndromes. Chest 112: 974-979, 1997. 
53. Song Z, Wu H, Cao H, Tang M, Yang S and Qin L: Nephrotic syndrome with acute pulmonary embolism in young adults: Two case reports. Medicine (Baltimore) 97: e11495, 2018.

54. Prandoni P, Lensing AW, Prins MH, Ciammaichella M, Perlati M, Mumoli N, Bucherini E, Visonà $\mathrm{A}$, Bova $\mathrm{C}$, Imberti $\mathrm{D}$, et al: Prevalence of pulmonary embolism among patients hospitalized for syncope. N Engl J Med 375: 1524-1531, 2016.

55. Le Gal G, Righini M, Roy PM, Meyer G, Aujesky D, Perrier A and Bounameaux $\mathrm{H}$ : Differential value of risk factors and clinical signs for diagnosing pulmonary embolism according to age. J Thromb Haemost 3: 2457-2464, 2005.

56. Imberti $D$ and Barillari G; eXperience VTE Italian Group: Real-Life Management of Venous Thromboembolism With Rivaroxaban: Results From EXperience VTE, an Italian Epidemiological Survey. Clin Appl Thromb Hemost 24: 241-247, 2018.

57. Prandoni P, Lensing AW, Buller HR, Carta M, Cogo A, Vigo M, Casara D, Ruol A and ten Cate JW: Comparison of subcutaneous low-molecular-weight heparin with intravenous standard heparin in proximal deep-vein thrombosis. Lancet 339: 441-445, 1992.

58. Columbus Investigators, Büller HR, Gent M, Gallus AS Ginsberg J, Prins MH and Baildon R: Low-molecular-weight heparin in the treatment of patients with venous thromboembolism. N Engl J Med 337: 657-662, 1997.

59. Eekels JJM, Althaus K, Bakchoul T, Kroll H, Kiefel V, Nazy I, Lee LS, Sachs U, Warkentin TE and Greinacher A: An international external quality assessment for laboratory diagnosis of heparin-induced thrombocytopenia. J Thromb Haemost 17: 525-531, 2019.

60. Toda A, Uehara S, Inoue T, Utoh M, Kusama T, Shimizu M, Uno Y, Mogi M, Sasaki E and Yamazaki H: Effects of aging and rifampicin pretreatment on the pharmacokinetics of human cytochrome P450 probes caffeine, warfarin, omeprazole, metoprolol and midazolam in common marmosets genotyped for cytochrome P450 2C19. Xenobiotica 48: 720-726, 2018.

61. Prins MH, Lensing AW, Bauersachs R, van Bellen B, Bounameaux H, Brighton TA, Cohen AT, Davidson BL, Decousus H, Raskob GE, et al: Oral rivaroxaban versus standard therapy for the treatment of symptomatic venous thromboembolism: A pooled analysis of the EINSTEIN-DVT and PE randomized studies. Thromb J 11: 21, 2013.

62. Lopez-Jimenez L, Montero M, Gonzalez-Fajardo JA, Arcelus JI, Suárez C, Lobo JL and Monreal M; RIETE Investigators: Venous thromboembolism in very elderly patients: Findings from a prospective registry (RIETE). Haematologica 91: 1046-1051, 2006

63. Lim W, Dentali F, Eikelboom JW and Crowther MA: Meta-analysis: Low-molecular-weight heparin and bleeding in patients with severe renal insufficiency. Ann Intern Med 144: 673-684, 2006

64. Silverstein RL, Bauer KA, Cushman M, Esmon CT, Ershler WB and Tracy RP: Venous thrombosis in the elderly: More questions than answers. Blood 110: 3097-3101, 2007.

65. Limdi NA, Beasley TM, Baird MF, Goldstein JA, McGwin G, Arnett DK, Acton RT and Allon M: Kidney function influences warfarin responsiveness and hemorrhagic complications. J Am Soc Nephrol 20: 912-921, 2009.

66. Mangoni AA and Jackson SH: Age-related changes in pharmacokinetics and pharmacodynamics: Basic principles and practical applications. Br J Clin Pharmacol 57: 6-14, 2004.

67. Garcia D, Regan S, Crowther M, Hughes RA and Hylek EM: Warfarin maintenance dosing patterns in clinical practice: Implications for safer anticoagulation in the elderly population. Chest 127: 2049-2056, 2005.

68. Campbell NR, Hull RD, Brant R, Hogan DB, Pineo GF and Raskob GE: Aging and heparin-related bleeding. Arch Intern Med 156: 857-860, 1996
69. Ageno W, Gallus AS, Wittkowsky A, Crowther M, Hylek EM and Palareti G: Oral anticoagulant therapy: Antithrombotic therapy and prevention of thrombosis, 9th edition: American College of Chest Physicians Evidence-Based Clinical Practice Guidelines. Chest 141 (Suppl 2): e44S-e88S, 2012.

70. Cook LM, Kahn SR, Goodwin J and Kovacs MJ: Frequency of renal impairment, advanced age, obesity and cancer in venous thromboembolism patients in clinical practice. J Thromb Haemost 5: 937-941, 2007.

71. Barba R, Marco J, Martin-Alvarez H, Rondon P, Fernández-Capitan C, Garcia-Bragado F and Monreal M; RIETE investigators: The influence of extreme body weight on clinical outcome of patients with venous thromboembolism: Findings from a prospective registry (RIETE). J Thromb Haemost 3: 856-862, 2005.

72. Steffel J, Verhamme P, Potpara TS, Albaladejo P, Antz M, Desteghe L, Haeusler KG, Oldgren J, Reinecke H, Roldan-Schilling V, et al: The 2018 European Heart Rhythm Association Practical Guide on the use of non-vitamin K antagonist oral anticoagulants in patients with atrial fibrillation. Eur Heart J 39: 1330-1393, 2018.

73. Eriksson BI, Borris LC, Friedman RJ, Haas S, Huisman MV, Kakkar AK, Bandel TJ, Beckmann H, Muehlhofer E, Misselwitz F, et al: Rivaroxaban versus enoxaparin for thromboprophylaxis after hip arthroplasty. N Engl J Med 358: 2765-2775, 2008.

74. Eikelboom JW, Connolly SJ, Bosch J, Dagenais GR, Hart RG, Shestakovska O, Diaz R, Alings M, Lonn EM, Anand SS, et al: Rivaroxaban with or without Aspirin in Stable Cardiovascular Disease. N Engl J Med 377: 1319-1330, 2017.

75. Geldhof V, Vandenbriele C, Verhamme P and Vanassche T: Venous thromboembolism in the elderly: Efficacy and safety of non-VKA oral anticoagulants. Thromb J 12: 21, 2014.

76. Greinacher A, Thiele T and Selleng K: Reversal of anticoagulants: An overview of current developments. Thromb Haemost 113: 931-942, 2015.

77. van Bellen B, Bamber L, Correa de Carvalho F, Prins M, Wang $M$ and Lensing AW: Reduction in the length of stay with rivaroxaban as a single-drug regimen for the treatment of deep vein thrombosis and pulmonary embolism. Curr Med Res Opin 30: 829-837, 2014.

78. Lefebvre P, Coleman CI, Bookhart BK, Wang ST, Mody SH, Tran KN,Zhuo DY, Huynh L and Nutescu EA: Cost-effectiveness of rivaroxaban compared with enoxaparin plus a vitamin $\mathrm{K}$ antagonist for the treatment of venous thromboembolism. J Med Econ 17: 52-64, 2014

79. Merli GJ, Hollander JE, Lefebvre P, Laliberté F, Raut MK, Germain G, Bookhart B and Pollack CV: Costs of hospital visits among patients with deep vein thrombosis treated with rivaroxaban and LMWH/warfarin. J Med Econ 19: 84-90, 2016.

80. Ho P, Brooy BL, Hayes L and Lim WK: Direct oral anticoagulants in frail older adults: A geriatric perspective. Semin Thromb Hemost 41: 389-394, 2015.

81. Siegal DM, Curnutte JT, Connolly SJ, Lu G, Conley PB, Wiens BL, Mathur VS, Castillo J, Bronson MD, Leeds JM, et al: Andexanet Alfa for the Reversal of Factor Xa Inhibitor Activity. N Engl J Med 373: 2413-2424, 2015.

This work is licensed under a Creative Commons Attribution-NonCommercial-NoDerivatives 4.0 International (CC BY-NC-ND 4.0) License. 